\title{
Public Health Impact and Cost-Effectiveness Analysis of Routine Infant 4CMenB Vaccination in Germany to Prevent Serogroup B Invasive Meningococcal Disease
}

\author{
Stefan Scholz • Magdalena Schwarz (D) - Ekkehard Beck • \\ Kinga Meszaros • Melanie Schneider • Bernhard Ultsch • \\ Wolfgang Greiner
}

Received: October 18, 2021 / Accepted: November 22, 2021

(c) GlaxoSmithKline Biologicals SA 2021, Corrected publication 2022

\section{ABSTRACT}

Introduction: Invasive meningococcal disease (IMD) is an uncommon, severe, life-threatening disease primarily affecting infants, with potential lifelong sequelae. Neisseria meningitidis (Nm) serogroup B (MenB) causes most IMD cases in Germany, many of which can be prevented with four-component MenB (4CMenB) vaccination. The potential public health and economic impact of introducing routine $4 \mathrm{CMenB}$ infant vaccination in Germany was assessed.

Methods: A dynamic transmission-based costeffectiveness model adapted for Germany assessed the impact of infant $4 \mathrm{CMenB}$ universal mass vaccination (UMV) versus no vaccination. The model included the latest real-world evidence on vaccine effectiveness, the comprehensive burden of disease on patients (sequelae)

Stefan Scholz and Magdalena Schwarz are co-first authors.

Supplementary Information The online version contains supplementary material available at https:// doi.org/10.1007/s40121-021-00573-w.

S. Scholz · W. Greiner

Bielefeld University, Bielefeld, Germany

M. Schwarz $(\bowtie) \cdot$ M. Schneider · B. Ultsch GSK, Prinzregentenplatz 9, 81675 Munich, Germany e-mail: magdalena.x.schwarz@gsk.com

E. Beck · K. Meszaros

GSK, Wavre, Belgium and their family (quality of life impact), comprehensive German IMD costs, and vaccination uptake assumptions.

Results: The largest public health impact was predicted in children: a rapid decline, 5 years after UMV implementation, of 39.9\% (34.7\%) for MenB (all IMD) cases aged 0-4 years and $42.4 \%(36.8 \%)$ in infants. Over lifetime (100year time horizon), 4CMenB could prevent 3154 MenB (3303 all IMD) cases, 291 MenB (304 all IMD) deaths and 1370 MenB (1435 all IMD) long-term sequelae. 4CMenB saved 25,878 quality-adjusted life-years (QALYs), at a cost of $€ 188,762$ per QALY gained in the base case (societal perspective including lost productivity). Scenarios including potential $\mathrm{Nm}$ carriage protection (enabling herd protection) or societal preferences for the prevention of severe diseases led to more cost-effective results, while a scenario excluding IMD impact beyond the patient with increased discounting of vaccination health benefits produced less cost-effective results.

Conclusions: MenB IMD is a vaccine-preventable disease. This analysis for Germany can inform decision-makers on the potential impact of introducing infant $4 \mathrm{CMenB}$ UMV. The program is predicted to rapidly produce health benefits (reduction in child cases, deaths and sequelae) at a cost per QALY to society of around $€ 190,000$ (base case), decreasing to around $€ 78,000$ when considering societal preferences and IMD underreporting. 


\section{PLAIN LANGUAGE SUMMARY}

Invasive meningococcal disease (IMD) is an uncommon but severe infection, usually presenting as meningitis and/or sepsis, caused by the bacteria Neisseria meningitidis. Most cases occur in infants, young children and adolescents. Patients who survive the disease can develop lifelong sequelae, such as physical, neurological and psychological/behavioural problems that impact their quality of life and that of their family/caregivers. This disease can be prevented by vaccination. The use of the four-component meningococcal serogroup B vaccine $(4 \mathrm{CMenB})$ in countries like Germany can prevent the most common form of this disease, IMD caused by serogroup B. This study assessed the public health and economic impact of infant vaccination in Germany with 4CMenB. For this, the authors used an economic model that measured the lifetime impact of the disease on patients but also on their families. The model predicted that after 5 years of vaccination, the number of cases and deaths in infants and young children aged $0-4$ years would rapidly decrease by almost $40 \%$. Over a long-term horizon of 100 years, this number was predicted to remain stable. Due to the reduced number of cases, vaccination would also result in fewer deaths and patients with sequelae, as well as cost savings for the healthcare system and society due to the reduced loss of productivity. In conclusion, in Germany, IMD caused by serogroup B is preventable through vaccination, and the $4 \mathrm{CMenB}$ vaccine in German infants is predicted to rapidly reduce the disease burden, save lives and prevent healthcare costs.

Keywords: 4CMenB; $\quad$ Cost-effectiveness; Germany; Infant; Meningococcal disease; Vaccination

\section{Key Summary Points}

\section{Why carry out this study?}

Invasive meningococcal disease (IMD) is uncommon, severe and life-threatening.

Most IMD cases in Germany are due to serogroup B, preventable with the fourcomponent meningococcal serogroup $B$ vaccine (4CMenB).

The public health and economic impact of introducing a universal infant 4CMenB immunisation program was modelled to inform decision-making in Germany.

\section{What was learned from the study?}

4CMenB could prevent 3154 (3303) cases, 291 (304) deaths and 1370 (1435) sequelae due to serogroup B IMD (all serogroups IMD), respectively, over 100 years.

The cost per quality-adjusted life year gained was around $€ 189,000$ from a societal perspective.

\section{INTRODUCTION}

Neisseria meningitidis ( $\mathrm{Nm}$ ) bacteria are present in the nasopharynx of around $10 \%$ of the adult population and up to $25 \%$ of adolescents, without causing symptoms $[1,2]$. However, if the pathogen penetrates the mucosal barrier in the absence of type-specific immunity, severe and life-threatening invasive meningococcal disease (IMD) may occur. IMD is an uncommon infectious disease with the highest incidence typically seen in infants. IMD has an unpredictable incidence, risk of outbreaks and occasional epidemics, with $\mathrm{Nm}$ serogroups varying by region and over time [3]. In 2019, around 256 cases of IMD were reported in Germany, representing an incidence of 0.3 IMD cases per 100,000 persons. The highest incidence (IMD cases per 100,000 persons) was seen in infants 
(2.8), 1-year-olds (1.9) and young adults 15-19 and 20-24 years of age (0.5 and 0.6) [4]. Patients typically presented with meningitis $(60 \%$ of cases), septicaemia (75\% of cases) or both $(35 \%$ of cases) [4]. Patients with IMD may die within hours after symptoms appear, even if they are rapidly treated and hospitalised. At discharge from hospital, up to $51.6 \%$ of infant survivors [5] (and around 30\% of survivors overall [6]) will have one or more sequelae that can be lifelong and of varying severity, including a range of physical, neurological and psychological or behavioural conditions (e.g. physical disability due to limb amputations, or hearing loss) [7]. Thus, IMD can have a lifelong impact on patients, affecting their quality of life, education and ability to work, as well as an impact on the quality of life and productivity of their family, especially if patients with IMD suffer from severe sequelae with the need for lifelong caregiving [7].

There are five $\mathrm{Nm}$ serogroups that cause the most IMD in Europe: serogroups A, B, C, W and $\mathrm{Y}$. Since the introduction of universal mass vaccination (UMV) to control $\mathrm{Nm}$ serogroup C (MenC) IMD in Europe (e.g. introduced in 2006 in Germany for children from 12 months of age [8]), Nm serogroup B (MenB) became the predominant cause of IMD. In 2019, 61\% of all notified IMD cases in Germany were caused by MenB [4]. The four-component MenB vaccine (4CMenB), licensed in the European Union in 2013, is the only serogroup B vaccine for infants. In Europe, 4CMenB infant vaccination is already included as UMV in the United Kingdom (UK), Ireland, Portugal, Czech Republic, Lithuania, Malta, Italy (including San Marino), Andorra [9] as well as Austria [10] and recently France [11]. After the first 3 years of 4CMenB UMV introduction in the UK in 2015, and based on the high vaccination uptake achieved (i.e. around $93 \%$ and $88 \%$ of children receiving two doses by 12 months of age and three doses by 24 months of age), there was a $75 \%$ reduction in observed incidence in the vaccine-eligible age group [12].

In Germany, the Standing Committee on Vaccination (Ständige Impfkommission, STIKO) is the independent National Immunization Technical Advisory Group (NITAG) that recommends vaccines for inclusion in the national vaccination schedule with subsequent mandatory reimbursement by the statutory health insurance. Decision-making by STIKO is usually supported by epidemiologic and economic modelling studies. A previous health economic analysis of childhood 4CMenB UMV in Germany, by Christensen et al. [13], estimated incremental cost-effectiveness ratios (ICERs) of over $€ 1.9$ million per quality-adjusted life year (QALY) gained excluding indirect effects. The STIKO recommended $4 \mathrm{CMenB}$ vaccination since 2015 for certain risk groups and, to prevent outbreaks, for post-exposure vaccination of unvaccinated household contacts of a patient with IMD [14] and decided not to include $4 \mathrm{CMenB}$ infant vaccination in the national immunization schedule during their reassessment in 2018 [15] due to further evidence needed (e.g. on vaccine effectiveness, safety and carriage protection). Since 2018, new evidence has become available filling in these and other evidence gaps, such as the burden and costs of IMD in Germany. A recent study analysing the clinical and economic burden of IMD in Germany found that hospitalised IMD cases had a risk of mortality of $5.5 \%$ in the first year after IMD and $24 \%$ of survivors had some form of sequelae (e.g. chronic renal failure, epilepsy, blindness and learning disabilities). While this analysis did not include any longterm costs or indirect costs, IMD cases were found to have significantly higher initial hospitalisation costs and rates of hospitalisation during the follow-up period versus matched controls [16]. A cost-of-illness model estimated MenB IMD lifetime costs in Germany and predicted a significant direct cost per patient of $€ 54,300$, primarily due to sequelae management costs. Total costs per case were $€ 57,100$ or $€ 171,000$, using the friction-cost approach (FCA) and human capital approach (HCA) for indirect costs, respectively. Based on a hypothetical cohort of around 340 cases in Germany, lifetime societal costs were around $€ 20$ million (FCA) to nearly €60 million (HCA) [17].

Based on new evidence available on the $4 \mathrm{CMenB}$ vaccine, as well as the humanistic and economic burden of IMD, the objective of this analysis was to reassess the potential public 
health impact and cost-effectiveness of introducing infant 4CMenB UMV in Germany.

\section{METHODS}

A dynamic transmission-based cost-effectiveness model (DyCE) [18] was adapted to the German setting to compare the impact of 4CMenB infant UMV (at 2, 4 and 12 months of age) versus no vaccination on the humanistic and economic burden due to MenB IMD and all IMD. To exclude the potential impact of the MenB vaccination recommendation for risk groups from September $2015[14,19]$ on the burden of MenB IMD/IMD, the model analysis was started in 2015, hence, starting in a setting assuming no vaccination. The model used $\mathrm{Nm}$ serogroup-specific input data wherever available, otherwise IMD data were applied (Supplemental Table S1).

\section{Model Structure}

The model (Supplemental Fig. S1) has been previously published for England and described in detail (Beck et al. [18]). Briefly, the model includes a dynamic transmission component, adapted with German demographic data, IMD incidence and data on the contacts from the POLYMOD study for Germany [20], to generate age-specific IMD cases in the arms with and without $4 \mathrm{CMenB}$ routine vaccination. The model can calculate direct and indirect effects of vaccination, such as $4 \mathrm{CMenB}$ cross-protection against other non-MenB IMD (i.e. serogroups $\mathrm{W}$ and $\mathrm{Y}$ IMD), and the potential effects on reducing $\mathrm{Nm}$ carriage and therefore transmission, resulting in herd protection. With a time horizon of 100 years, the model's economic decision-tree component determines the health states associated with each IMD case over their lifetime. The model uses probabilities of death due to IMD in the acute phase, of surviving without sequelae, or of surviving with one or more of a range of up to 16 possible sequelae based on MenB IMD observational studies [6, 21] (multiple sequelae can occur independently of each other). The costs and QALYs associated with each health state are applied to MenB (all IMD) cases in each arm of the decision tree, to assess the ICER of $4 \mathrm{CMenB}$ infant UMV versus no vaccination.

\section{Quality of Life, Demographic and Economic Inputs}

QALYs were calculated for non-fatal cases and premature deaths during the acute phase of IMD and for sequelae, using the utility weights listed in Supplemental Table S1 and populations norms for Germany [22]. The life expectancy at age of IMD onset taken from German lifetables [23] was used to calculate the overall QALY loss per case. Health spillover effects (i.e. QALY losses beyond the patient for the family/caregivers and formal long-term caregivers [24, 25] as well as a bereavement factor $[26,27])$ were included in the QALY losses due to IMD (see Supplemental Table S1).

A bottom-up age-specific IMD costing approach for Germany was used and is described in Scholz et al. [17]. In summary, costs in the acute phase included hospitalisation, public health response (e.g. contact tracing and chemoprophylaxis) and indirect costs due to premature mortality and productivity loss in IMD cases. Following the acute phase, direct costs for life-long sequelae included inpatient and outpatient care, rehabilitation, special education and long-term care (calculated for year 1 and for subsequent years). Indirect costs included lost productivity in IMD cases of working age (15-65 years) and in one parent of childhood IMD cases [17].

\section{Vaccine Inputs}

Clinical trial immunogenicity data are now confirmed by real-world evidence showing 79\% vaccine effectiveness against MenB IMD in fully vaccinated people (after two or more doses according to age), from a recently published case-control study in Portugal [28]. 4CMenB uptake by the age of 12 months increased in Portugal from around 33\% in the 2015 birth cohort to $57 \%$ in 2018, and there were sufficient numbers of MenB IMD cases during the case-control study, in particular among 
controls, to provide a robust estimate of vaccine effectiveness reaching statistical significance [28]. At the time of the study, a $3+1$ schedule was used in infants, with a $2+1$ schedule recommended later in January 2018 by the Portuguese Society of Paediatrics [29]; however, non-inferiority was demonstrated for immunogenicity of the $2+1$ versus $3+1$ schedule [30] and therefore the model uses these vaccine effectiveness values. This model was previously used in the UK [18], and the impact of 4 CMenB using the Portuguese vaccine effectiveness estimates provided comparable vaccine impact results to those observed from real-world data after 3 years of routine $4 \mathrm{CMenB}$ infant vaccination [12]. Model vaccine effectiveness against MenB IMD was assumed to be 0\% after the first dose (conservative assumption) and 79\% after the second and booster doses. Vaccine uptake for the first, second and booster dose was assumed to be $92 \%, 91 \%$ and $71 \%$, respectively, based on applying a 5\%-point reduction to pneumococcal vaccination coverage rates in Germany [31]. Waning was conservatively modelled using the estimated mean duration of protection of 33 months after the second dose and 38 months after the booster dose [30, 32].

The 4CMenB vaccine has shown potent serum bactericidal antibody activity against serogroups C, W and Y, with $68 \%$ of $\mathrm{Nm}$ serogroup W (MenW) strains and $87 \%$ of $\mathrm{Nm}$ serogroup Y (MenY) strains killed [33]. As there is no real-world evidence to estimate the vaccine effectiveness for cross-protection against IMD serogroups $\mathrm{C}, \mathrm{W}$ and $\mathrm{Y}$, these human serum bactericidal assay killing estimates were applied in the base case to approximate the vaccine effectiveness against serogroups $\mathrm{W}$ and Y. The model assumed no 4CMenB cross-protection against $\mathrm{Nm}$ serogroup A (MenA) or MenC IMD (due to the MenC UMV in place and very low incidence of serogroup A). Further, cross-protection against MenW and MenY was assumed only for individuals that are fully protected against MenB IMD, resulting in a conservative overall cross-protection estimate of $23.8 \%$ against $\mathrm{Nm}$ serogroups $\mathrm{A}, \mathrm{C}, \mathrm{W}$, and $\mathrm{Y}$ (MenACWY).

Adverse events associated with 4CMenB vaccination include solicited local and systemic reactions that are transient and mild or moderate in nature, as observed in clinical trials [34] and confirmed by real-world data from the UK [35] and Germany [36, 37]. The model included costs related to medically attended fever. The adverse event rate was based on the frequency of medically attended fever for $4 \mathrm{CMenB}$ plus routine vaccines versus routine infant vaccinations, i.e. an incremental $0.48 \%$ for primary doses in infants [34]. 4CMenB infant UMV with vaccination at 2,4 and 12 months of age could imply co-administration of $4 \mathrm{CMenB}$ with the measles, mumps, rubella and varicella vaccine (MMRV) as a catch-up vaccination at 12 months of age according to the current German national immunisation calendar [38]. Thus, in the absence of incremental rates available, the absolute rate of $1.1 \%$ for medically attended fever (4CMenB plus MMRV) was applied for the booster dose [34]. Therefore, the rate of at least one adverse event with a full vaccination series $(2+1$ schedule) was estimated to be $1.99 \%$, assuming that adverse events occur independently of each other. Among these adverse events, $8.8 \%$ were calculated to need a hospital inpatient stay (see Supplemental Table S2) $[34,39]$.

The model used a vaccine price of $€ 97.06$ per dose (i.e. average payer price per dose across all 17 German healthcare regions via office supply [40]), with a corresponding wholesale price of $€ 77.00$ and assumed administration cost of $€ 7.60$ per dose, based on the average cost of administration for vaccines.

Further details of the model structure and input parameters are provided in Supplemental Fig. S1 and Table S1.

\section{Calibration and Epidemiologic Inputs}

As in the model by Christensen et al. [13], this model was calibrated in a two-step process: in the first step, the dynamic model was calibrated to the age-specific carriage prevalence reported by Christensen et al. [2]; and in the second step, the case-carrier ratio (used to calculate the number of IMD cases from the carriers in the decision tree) was calibrated to the age-specific IMD incidence in Germany. As IMD incidence 
varies unpredictably each year with outbreaks and periods of endemic disease [41], an average of incidence data over the period 2007 to 2015 was used, to account for the impact of MenC UMV starting in 2006, and to exclude a low MenB vaccination effect since MenB vaccination recommendation for risk groups was implemented in 2016. National surveillance data [42] were used to estimate IMD cases by yearly age groups ( 0 to $99+$ years of age) for serogroups A, B, C, W, Y, X and "Other".

\section{Analysis}

The public health impact was assessed in terms of reduction in overall IMD and MenB IMD incidence and numbers of cases and deaths following the introduction of $4 \mathrm{CMenB}$ infant UMV. The model also estimated the number needed to vaccinate (NNV) to prevent one case of MenB IMD (all IMD) (i.e. total number of vaccinations divided by total number of cases prevented), and number of adverse events expected post-vaccination to prevent one case of MenB IMD (all IMD) (i.e. NNV multiplied by rate of at least one adverse event with a full 4 CMenB vaccination series $[2+1$ schedule]).

For the cost-effectiveness analysis of $4 \mathrm{CMenB}$ infant UMV, the key base case assumptions with alternatives implemented in each scenario analysis are presented in Table 1. Although the STIKO recommends a 3\% discount rate for health outcomes in the base case and $1 \%$ in uncertainty analyses, the model used a $1 \%$ base case discount rate to account for the long-term impact of IMD [43]. In addition to the QALY losses for premature death and from sequelae in patients, the base case assumed a humanistic burden on the family and network of patients with IMD, with health spillover effects (i.e. family/network QALY losses) [24], a bereavement factor $[26,27]$ and a QALY loss for formal long-term caregivers [25] of IMD survivors with severe long-term sequelae. To account for the long-term negative health impact experienced by the family and close network of patients with IMD, as shown in a UK study, the QALY losses of patients due to acute disease and survivors with long-term sequelae were multiplied by a family and network factor of $48 \%$ [24]. The impact of death on the family was considered by applying a bereavement factor of 9\% [27] to QALYs lost in fatal cases. For formal long-term caregivers of IMD survivors with severe sequelae, a utility decrement of 0.11 was assumed. A progressive scenario was developed, adding to the base case: (a) a quality of life adjustment factor (QAF) of 3, applied to QALY loss in cases with long-term sequelae, as previously recommended by the UK Joint Committee on Vaccination and Immunisation (JCVI) [44] and used in Christensen et al. (2014 and $2017[26,45])$, to account for the societal preference to prevent uncommon but severe diseases such as IMD; and (b) incidence increased by $16.7 \%$ to account for potential underreporting (based on estimates for Germany [17]). A formal scenario applying the specifications for base case analysis according to the standard operating procedure (SOP) [43] of the STIKO was developed (STIKO SOP scenario), applying 3\% discount rates for both costs and QALYs, and not considering the humanistic burden beyond the patient or any of the additional factors considered in the progressive scenario. The impact of varying discount rates (between 0 and $5 \%$ ) on the $4 \mathrm{CMenB}$ cost-effectiveness was assessed in scenario analyses for the base case and STIKO SOP scenario (Supplemental Table S3). Recent evidence from Australia suggests $4 \mathrm{CMenB}$ is not likely to have an effect on carriage [46] and therefore no carriage effect was assumed in the base case. As a further extension of the base case, a carriage scenario assessed the potential effectiveness of $4 \mathrm{CMenB}$ in preventing acquisition of $\mathrm{Nm}$ carriage of MenB and MenACWY [47], and thus the impact of herd protection. Finally, to account for occasional epidemics and natural fluctuations of IMD incidence [48], high and low incidence scenarios were conducted with the incidence multiplied by 3 and 0.5 , respectively. All input parameters are described in Supplemental Table S1.

As recommended by the STIKO [43], the base case analysis adopted the societal perspective, i.e. including direct costs reimbursed by the Statutory Health Insurance (SHI), costs of nonreimbursed patient co-payments and lost 
Table 1 Base case assumptions and alternatives used in scenario analysis

\begin{tabular}{|c|c|c|c|c|c|c|}
\hline & Base case $^{a}$ & $\begin{array}{l}\text { Progressive } \\
\text { scenario }\end{array}$ & $\begin{array}{l}\text { STIKO } \\
\text { SOP } \\
\text { scenario }^{a}\end{array}$ & Carriage scenario & $\begin{array}{l}\text { High } \\
\text { incidence } \\
\text { scenario }\end{array}$ & $\begin{array}{l}\text { Low incidence } \\
\text { scenario }\end{array}$ \\
\hline \multicolumn{7}{|l|}{ Discounting [43] } \\
\hline Costs & $3 \%$ & $3 \%$ & $3 \%$ & $3 \%$ & $3 \%$ & $3 \%$ \\
\hline QALYs & $1 \%$ & $1 \%$ & $3 \%$ & $1 \%$ & $1 \%$ & $1 \%$ \\
\hline \multicolumn{7}{|l|}{ Family burden } \\
\hline $\begin{array}{l}\text { Bereavement } \\
\text { factor }[27]\end{array}$ & $\begin{array}{l}\text { QALY loss } \\
\text { in fatal } \\
\text { cases } \\
+9 \%\end{array}$ & $\begin{array}{l}\text { QALY loss in } \\
\text { fatal cases } \\
+9 \%\end{array}$ & NA & $\begin{array}{l}\text { QALY loss in fatal } \\
\text { cases }+9 \%\end{array}$ & $\begin{array}{l}\text { QALY loss in } \\
\text { fatal cases } \\
+9 \%\end{array}$ & $\begin{array}{l}\text { QALY loss in } \\
\text { fatal cases } \\
+9 \%\end{array}$ \\
\hline $\begin{array}{l}\text { Family and } \\
\text { network factor } \\
{[24]}\end{array}$ & $\begin{array}{l}\text { QALY loss } \\
\text { of } \\
\text { survivors } \\
+48 \%\end{array}$ & $\begin{array}{l}\text { QALY loss of } \\
\text { survivors } \\
+48 \%\end{array}$ & NA & $\begin{array}{l}\text { QALY loss of } \\
\text { survivors }+48 \%\end{array}$ & $\begin{array}{l}\text { QALY loss of } \\
\text { survivors } \\
+48 \%\end{array}$ & $\begin{array}{l}\text { QALY loss of } \\
\text { survivors } \\
+48 \%\end{array}$ \\
\hline $\begin{array}{l}\text { Formal long- } \\
\text { term caregiver } \\
\text { disutility [25] }\end{array}$ & $\begin{array}{c}\text { Disutility } \\
0.11\end{array}$ & Disutility 0.11 & NA & Disutility 0.11 & Disutility 0.11 & Disutility 0.11 \\
\hline $\begin{array}{l}\text { 4CMenB carriage } \\
\text { effect }[47]\end{array}$ & NA & NA & NA & $\begin{array}{c}\text { 15.6\% MenB, 29.6\% } \\
\text { MenACWY } \\
\text { carriage reduction }\end{array}$ & NA & NA \\
\hline $\begin{array}{l}\text { QAF for societal } \\
\text { preference }[44]\end{array}$ & NA & $\begin{array}{l}\text { QALY loss long- } \\
\text { term sequelae } \\
\text { cases } \times 3\end{array}$ & NA & NA & NA & NA \\
\hline $\begin{array}{l}\text { IMD potential } \\
\text { underreporting } \\
{[17]}\end{array}$ & NA & $\begin{array}{c}\text { Incidence } \\
\text { increase } \\
16.7 \%\end{array}$ & NA & NA & NA & NA \\
\hline $\begin{array}{l}\text { Incidence } \\
\text { multiplier } \\
\text { (assumptions) }\end{array}$ & NA & NA & NA & NA & Incidence $\times 3$ & Incidence $\times 0.5$ \\
\hline
\end{tabular}

$4 C M e n B$ four-component meningococcal serogroup B vaccine; IMD invasive meningococcal disease; $M e n A C W Y$ meningococcal serogroups A, C, W, Y; MenB meningococcal serogroup B; $N A$ not applicable; $Q A F$ quality of life adjustment factor; QALY quality-adjusted life year; SOP standard operating procedure; STIKO Standing Committee on Vaccination (Ständige Impfkommission)

${ }^{a}$ Further scenario analyses on discount rates were applied to the base case and STIKO SOP scenario (Supplemental Table S3)

productivity costs (using the FCA to be applied for death and the acute phase of disease and the HCA to be applied for long-term sequelae including parents staying at home) in patients and their caregivers. Costs were expressed in euros $(€)$ for the reference year 2015. 
Both deterministic and probabilistic sensitivity analyses (DSA and PSA) were carried out to assess structural and parameter uncertainty. A univariate DSA was performed on all input parameters, while a PSA with $n=1000$ replications was performed for the base case scenario excluding normative variables (i.e. discount rates, vaccine price and administration costs) as recommended by STIKO [43] and assuming no carriage protection and no QAF. As there is no official cost-effectiveness threshold in Germany [43], hypothetical thresholds of one, two, and three times the gross domestic product (GDP) per capita were applied, as proposed by the World Health Organization (WHO) [49], with ICERs below $€ 37,046$ and $€ 111,138$ representing a highly cost-effective and a cost-effective intervention [50]. For the PSA, the likelihood of replications having an ICER below WHO's costeffectiveness thresholds and the percentage of runs below the base case ICER were derived. The parameters with ranges used for the DSA and distributions for the PSA can be found in Supplemental Table S1.

\section{Compliance with Ethics Guidelines}

This analysis uses data from previously conducted studies and does not contain any new studies with human participants or animals performed by any of the authors.

\section{RESULTS}

\section{Public Health Impact}

Following introduction of 4CMenB infant $\mathrm{UMV}$, the model predicts a rapid decline in IMD incidence, primarily due to a reduction in MenB IMD. Figure 1 shows the impact of $4 \mathrm{CMenB}$ UMV on IMD incidence (MenB IMD and all IMD) in the age group 0-4 years over 100 years.

The largest public health impact was predicted in the group directly benefitting from vaccination, i.e. the age group of infants and children 0-4 years of age at highest risk. Herd protection was not considered in the base case. Among infants and young children aged
$0-4$ years, the model estimated there would be 497 MenB IMD (597 IMD) cases and 47 (56) deaths over 5 years (7687 MenB IMD [9239 IMD] cases and 722 [868] deaths over 100 years) without vaccination. A $4 \mathrm{CMenB}$ infant UMV would rapidly prevent around 40\% (35\%) and $42 \%(37 \%)$ of MenB IMD (all IMD) cases and deaths in 0-4-year-olds and in infants, respectively, 5 years after implementation of routine vaccination. The case reduction would remain at this stable level over 100 years (i.e. prevention of around $40 \%(35 \%)$ and $42 \%(37 \%)$ of both MenB IMD [all IMD] cases and deaths with a 100-year time horizon in these age groups). Based on the clinical and real-world evidence on duration of protection, vaccine effectiveness and model assumptions around adverse event rates, the model calculated the NNV; the model predicted $12,080(11,536)$ infants would need to be vaccinated to prevent one case of MenB IMD (all IMD). Regarding adverse events (i.e. medically attended fever), there would be an estimated 241 (230) adverse events postvaccination leading to an estimated 21 (20) hospital inpatient stays to prevent one case of MenB IMD (all IMD).

\section{Health Outcomes and Cost-Effectiveness Results}

The 4 CMenB infant UMV is predicted to prevent 3154 MenB IMD (3303 IMD) cases, the development of 1370 (1435) long-term sequelae cases, 286 (300) cases needing long-term residential care and 291 (304) deaths, resulting in $10,023(10,491)$ life years saved and 24,720 $(25,878)$ QALYs gained over the model's time horizon of 100 years. Over half (56\%) of QALYs gained are due to prevention of sequelae and cases requiring long-term residential care (Table 2).

With no vaccination, MenB IMD (all IMD) disease management costs are estimated to be around $€ 464.8$ ( $€ 681.1$ ) million over the model time horizon, with a significant additional lost productivity cost to society of $€ 1.1$ ( $€ 1.6)$ billion in Germany. The $4 \mathrm{CMenB}$ infant UMV is predicted to reduce disease management costs by around $€ 75.4$ ( $€ 79.0)$ million (savings of $€ 9.5$ 


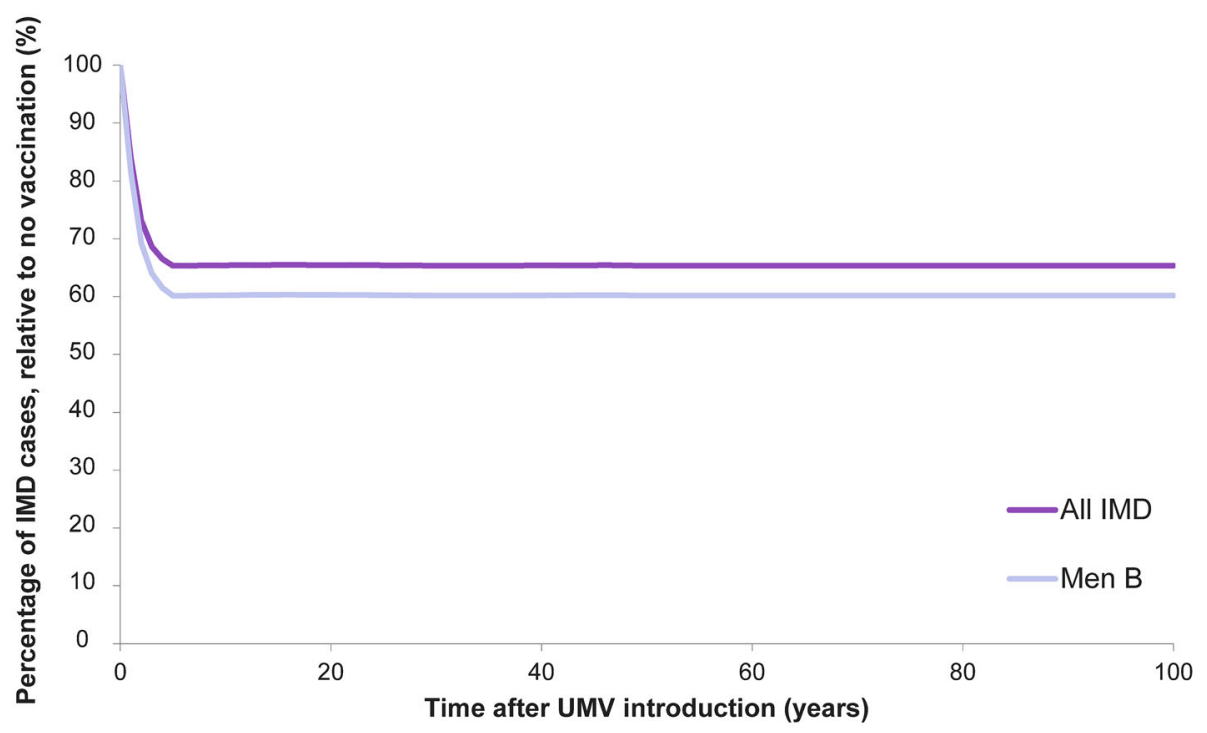

Fig. 1 Base case percentage reduction in invasive meningococcal disease (IMD) incidence due to meningococcal serogroup $\mathrm{B}(\mathrm{MenB})$ and all serogroups, relative to no vaccination (age group 0-4 years). UMV universal mass vaccination

[€10.0] million in acute care, $€ 55.4$ [€58.0] million in sequelae management, €9.6 [€10.0] million in special education costs and $€ 0.90$ [€0.94] million in public health outbreak management costs). When considering the significant impact of IMD on productivity, the UMV is predicted to save a total of $€ 222.0(€ 232.4)$ million in direct and indirect disease management costs (Table 3). The average annual undiscounted cost of vaccination was $€ 133.4$ million ( $€ 47.0$ million discounted).

Considering the health benefits, cost savings and vaccination program costs, introducing a 4 CMenB infant UMV in Germany is predicted to result in a gain in QALYs from prevention of IMD cases, sequelae and deaths, and increased costs driven by vaccination program costs, producing an incremental cost per QALY gained of $€ 188,762$ (including productivity losses) versus no vaccination (Table 4 ).

\section{Scenario Analyses}

The results of the scenario analyses compared to the base case are presented in Fig. 2 and Table 5. The STIKO SOP scenario, which produced a less cost-effective result (ICER $€ 817,348 / \mathrm{QALY}$ ) than the base case (ICER $€ 188,762 / \mathrm{QALY}$ ), excluded the QALY impact of IMD beyond the patient and applied a higher QALY discount rate (i.e. $3 \%$ vs. $1 \%$ in the base case). In the progressive scenario, assuming underreporting of IMD incidence and using the QAF to account for societal preferences, $4 \mathrm{CMenB}$ infant UMV appeared to be more cost-effective than the base case with an ICER of $€ 77,941 / \mathrm{QALY}$ versus $€ 188,762 / \mathrm{QALY}$, respectively. Taking into consideration the potential carriage effect of $4 \mathrm{CMenB}$ (and subsequent herd protection) resulted in more IMD cases averted, and therefore more QALYs gained, with a more cost-effective result (ICER $€ 109,090 / \mathrm{QALY}$ ) than in the base case (Table 5). Further, assuming a low and high incidence scenario (varying the incidence by $50 \%$ and $300 \%$ ) led to ICERs of $€ 386,375 /$ QALY and $€ 56,935 / \mathrm{QALY}$, respectively. The impacts of single parameter changes considered in the scenario analyses are presented in Fig. 2.

\section{Deterministic and Probabilistic Sensitivity Analyses}

Figure 3 shows the ICER results when varying input parameters in the DSA. Varying the discount rate for health outcomes (from 1\% to 5\%) had the largest impact on cost-effectiveness, followed by the discount rate for costs (using $1 \%$ and $5 \%$ ) and by MenB incidence (varying 
Table 2 Breakdown of all IMD cases, sequelae, deaths, QALYs and LYs lost (discounted 1\%)

\begin{tabular}{|c|c|c|c|}
\hline & No vaccination & 4CMenB & Difference* \\
\hline Total IMD cases* & 33,547 & 30,244 & 3303 \\
\hline B IMD cases & 22,274 & 19,120 & 3154 \\
\hline ACWY IMD cases & 10,287 & 10,139 & 149 \\
\hline Other IMD cases & 986 & 986 & 0 \\
\hline Total long-term sequelae cases* & 14,207 & 12,773 & 1435 \\
\hline Long-term physical sequelae & 2880 & 2589 & 291 \\
\hline Long-term neurological sequelae & 6021 & 5413 & 608 \\
\hline Long-term psychological/ behavioural sequelae & 5306 & 4770 & 536 \\
\hline Total long-term care cases & 2969 & 2669 & 300 \\
\hline Total deaths & 3856 & 3551 & 304 \\
\hline Total disc. LYs lost* & 90,212 & 79,721 & 10,491 \\
\hline LYs lost B IMD cases & 60,326 & 50,303 & 10,023 \\
\hline LYs lost ACWY IMD cases & 27,683 & 27,215 & 468 \\
\hline LYs lost Other IMD cases & 2202 & 2202 & 0 \\
\hline Total disc. QALYs lost* & 215,573 & 189,695 & 25,878 \\
\hline QALYs lost B IMD cases & 146,469 & 121,749 & 24,720 \\
\hline QALYs lost ACWY IMD cases & 62,963 & 61,804 & 1159 \\
\hline QALYs lost Other IMD cases & 6142 & 6142 & 0 \\
\hline Disc. acute care QALYs lost* & 5007 & 4511 & 497 \\
\hline Acute QALYs lost B IMD cases & 3340 & 2866 & 474 \\
\hline Acute QALYs lost ACWY IMD cases & 1515 & 1493 & 22 \\
\hline Acute QALYs lost Other IMD cases & 152 & 152 & 0 \\
\hline Disc. long-term sequelae QALYs lost* & 109,733 & 98,372 & 11,360 \\
\hline Sequelae QALYs lost B IMD cases & 74,691 & 63,954 & 10,737 \\
\hline Sequelae QALYs lost ACWY IMD cases & 31,513 & 30,891 & 623 \\
\hline Sequelae QALYs lost Other IMD cases & 3528 & 3528 & 0 \\
\hline
\end{tabular}

*Round off to the whole number may have introduced an error of $+/-1$ to addition or subtraction results $4 C M e n B$ four-component meningococcal serogroup B vaccine; $A C W Y / B / O t h e r I M D$ serogroups $\mathrm{A}, \mathrm{C}, \mathrm{W}$, Y/serogroup B/ serogroup Other invasive meningococcal disease; disc. discounted; $L Y$ life year; $Q A L Y$ quality-adjusted life year

the base case incidence by around plus or minus $25 \%$, see Supplement Table S1).

At the hypothetical WHO cost-effectiveness threshold values of one, two, and three times the GDP per capita of 2015 , routine 4 CMenB had a low probability of being cost-effective (Fig. 4). The percentage of PSA runs below the base case ICER of $€ 188,762$ was $52.3 \%$. 
Table 3 Breakdown of base case costs (€, discounted 3\%)

\begin{tabular}{|c|c|c|c|}
\hline & No vaccination & 4CMenB & Difference* $^{*}$ \\
\hline Acute care cost* & $103,034,307$ & $93,046,843$ & $-9,987,463$ \\
\hline B IMD cases & $68,111,652$ & $58,573,267$ & $-9,538,385$ \\
\hline ACWY IMD cases & $32,070,678$ & $31,621,600$ & $-449,078$ \\
\hline Other IMD cases & $2,851,976$ & $2,851,976$ & 0 \\
\hline Long-term sequelae direct medical cost* & $529,366,387$ & $471,353,279$ & $-58,013,108$ \\
\hline B IMD cases & $359,333,137$ & $303,923,317$ & $-55,409,820$ \\
\hline ACWY IMD cases & $153,302,192$ & $150,698,904$ & $-2,603,288$ \\
\hline Other IMD cases & $16,731,059$ & $16,731,059$ & 0 \\
\hline Special educational cost* & $38,394,072$ & $28,376,446$ & $-10,017,626$ \\
\hline B IMD cases & $30,513,964$ & $20,942,433$ & $-9,571,532$ \\
\hline ACWY IMD cases & $6,817,818$ & $6,371,724$ & $-446,094$ \\
\hline Other IMD cases & $1,062,289$ & $1,062,289$ & 0 \\
\hline Public health management and outbreak cost* & $10,291,620$ & $9,349,319$ & $-942,300$ \\
\hline B IMD cases & $6,794,113$ & $5,894,091$ & $-900,022$ \\
\hline ACWY IMD cases & $3,197,382$ & $3,155,103$ & $-42,278$ \\
\hline Other IMD cases & 300,125 & 300,125 & 0 \\
\hline Productivity loss cost (working age cases, parents) ${ }^{*}$ & $1,613,427,081$ & $1,459,972,962$ & $-153,454,119$ \\
\hline B IMD cases & $1,080,043,113$ & $933,485,497$ & $-146,557,616$ \\
\hline ACWY IMD cases & $479,847,168$ & $472,950,665$ & $-6,896,503$ \\
\hline Other IMD cases & $53,536,800$ & $53,536,800$ & 0 \\
\hline Total disease management cost* & $681,086,385$ & $602,125,888$ & $-78,960,497$ \\
\hline B IMD cases & $464,752,866$ & $389,333,108$ & $-75,419,758$ \\
\hline ACWY IMD cases & $195,388,070$ & $191,847,331$ & $-3,540,739$ \\
\hline Other IMD cases & $20,945,449$ & $20,945,449$ & 0 \\
\hline Total cost including productivity loss* & $2,294,513,467$ & $2,062,098,850$ & $-232,414,616$ \\
\hline B IMD cases & $1,544,795,979$ & $1,322,818,606$ & $-221,977,374$ \\
\hline ACWY IMD cases & $675,235,239$ & $664,797,996$ & $-10,437,242$ \\
\hline Other IMD cases & $74,482,248$ & $74,482,248$ & 0 \\
\hline Total vaccination, administration and $\mathrm{AE}$ cost* & 0 & $5,117,251,165$ & $+5,117,251,165$ \\
\hline Vaccination cost & 0 & $4,704,017,905$ & $+4,704,017,905$ \\
\hline Administration cost & 0 & $368,334,392$ & $+368,334,392$ \\
\hline $\mathrm{AE}$ cost & 0 & $44,898,868$ & $+44,898,868$ \\
\hline Total cost excluding productivity loss ${ }^{*, 1}$ & $681,086,385$ & $5,719,377,053$ & $+5,038,290,667$ \\
\hline
\end{tabular}


Table 3 continued

\begin{tabular}{lllc}
\hline & No vaccination & 4CMenB & Difference* $^{*}$ \\
\hline B IMD cases $^{1}$ & $464,752,866$ & $5,506,584,273$ & $+5,041,831,406$ \\
ACWY IMD cases $^{1}$ & $195,388,070$ & $5,309,098,496$ & $+5,113,710,426$ \\
Other IMD cases $^{1}$ & $20,945,449$ & $5,138,196,613$ & $+5,117,251,165$ \\
Total cost including productivity loss $^{* 1}$ & $2,294,513,467$ & $7,179,350,015$ & $+4,884,836,548$ \\
B IMD cases $^{1}$ & $1,544,795,979$ & $6,440,069,770$ & $+4,895,273,791$ \\
ACWY IMD cases $^{1}$ & $675,235,239$ & $5,782,049,161$ & $+5,106,813,922$ \\
Other IMD cases $^{1}$ & $74,482,248$ & $5,191,733,413$ & $+5,117,251,164$ \\
\hline
\end{tabular}

Negative differences represent cost savings following vaccination

*Round off to the whole number may have introduced an error of $+/-1$ to the addition or subtraction results

${ }^{1}$ Values represent the sum of disease management cost (total, B/ACWY/Other IMD cases), including/excluding productivity loss cost (total, $\mathrm{B} / \mathrm{ACWY} / O$ ther IMD cases) plus total vaccination, administration and $\mathrm{AE}$ cost $4 C M e n B$ four-component meningococcal serogroup B vaccine; $A C W Y / B /$ Other $I M D$ serogroups A, C, W, Y/B/Other invasive meningococcal disease; $A E$ adverse event

Table 4 Base case cost-effectiveness results for 4 CMenB infant UMV versus no vaccination (discounted at 1\% for QALYs and $3 \%$ for costs)

\begin{tabular}{llll}
\hline Base case & No vaccination & 4CMenB infant UMV & Incremental value \\
\hline Total costs incl. productivity loss, $€$ & $2,294,513,467$ & $7,179,350,015$ & $4,884,836,548$ \\
Total costs excl. productivity loss, $€$ & $681,086,385$ & $5,719,377,053$ & $5,038,290,667$ \\
Total QALYs lost & 215,573 & 189,695 & 25,878 \\
Incremental cost/QALY gained incl. productivity loss & & $€ 188,762$ \\
Incremental cost/QALY gained excl. productivity loss & & $€ 194,691$ \\
\hline
\end{tabular}

$4 C M e n B$ four-component meningococcal serogroup B vaccine; excl. excluding; incl. including; $Q A L Y$ quality-adjusted life year; $U M V$ universal mass vaccination

\section{DISCUSSION}

MenB (IMD) is an uncommon severe disease with potential life-threatening consequences, especially in infants. Introducing an infant 4CMenB UMV $(2+1$ dosing schedule at 2,4 and 12 months of age) in Germany would result in a rapid decline in MenB (all IMD) incidence and deaths in the most vulnerable group of infants and young children 0-4 years of age, especially with a rapid increase in vaccine uptake. The sustainable reduction in incidence would occur within the first 5 years of introducing the UMV, with reductions of around 40\% (35\%) in MenB (all IMD) cases and deaths in young children. This represents a reduction of 3154 MenB (3303 all IMD) cases, 1370 (1435) long-term sequelae cases, 286 (300) cases requiring long-term residential care and 291 (304) deaths. The program would reduce the burden of direct and indirect treatment costs, saving €75.4 (€79.0) million in disease and outbreak management costs and special education costs in the base case, with an average annual undiscounted cost of vaccination of $€ 133.4$ million. The infant UMV would reduce 


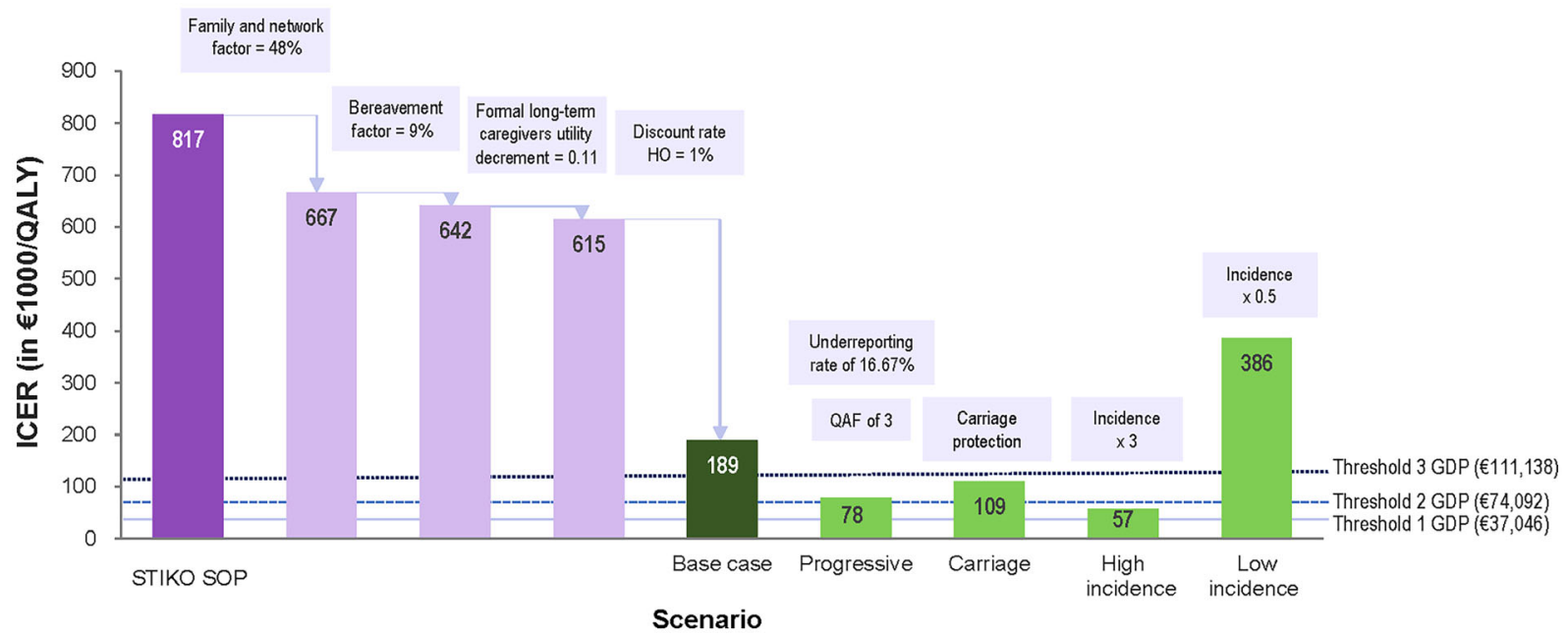

Fig. 2 Impact of single parameters considered in scenario analyses on the $4 \mathrm{CMenB}$ cost-effectiveness using a stepwise approach. Note: base case and scenarios to the right of the base case use discount rates of $3 \%$ for costs and $1 \%$ for HO. 4CMenB four-component meningococcal serogroup B vaccine; GDP gross domestic product; $\mathrm{HO}$ health outcomes; ICER incremental cost-effectiveness ratio; QAF quality of life adjustment factor; QALY quality-adjusted life year; SOP standard operating procedure; STIKO Standing Committee on Vaccination (Ständige Impfkommission)

Table 5 Scenario analyses results (discounted), all age groups

\begin{tabular}{|c|c|c|c|c|c|}
\hline Scenario analysis & $\begin{array}{l}\text { IMD } \\
\text { cases } \\
\text { averted }\end{array}$ & $\begin{array}{l}\text { MenB } \\
\text { cases } \\
\text { averted }\end{array}$ & $\begin{array}{l}\text { Incremental } \\
\text { QALYs }\end{array}$ & $\begin{array}{l}\text { Incremental } \\
\text { costs }\end{array}$ & ICER \\
\hline Base case $^{\mathrm{a}}$ (disc. 3\% costs, 1\% QALYs) & 3303 & 3154 & 25,878 & $€ 4,884,836,548$ & $€ 188,762$ \\
\hline $\begin{array}{l}\text { Progressive scenario: disc. 1\% QALYs, QAF = 3, } \\
\text { underreporting } 16.7 \%\end{array}$ & 3963 & 3785 & 62,077 & $€ 4,838,353,615$ & $€ 77,941$ \\
\hline $\begin{array}{l}\text { STIKO SOP scenario }{ }^{a} \text { disc. 3\% QALYs, no } \\
\text { bereavement/family or caregivers QALY loss }\end{array}$ & 3303 & 3154 & 5976 & $€ 4,884,836,548$ & $€ 817,348$ \\
\hline Carriage scenario & 6688 & 4464 & 43,594 & $€ 4,755,696,991$ & $€ 109,090$ \\
\hline High incidence scenario & 9907 & 9462 & 77,633 & $€ 4,420,025,290$ & $€ 56,935$ \\
\hline Low incidence scenario & 1652 & 1577 & 12,943 & $€ 5,001,000,476$ & $€ 386,375$ \\
\hline
\end{tabular}

disc. discounted; ICER incremental cost-effectiveness ratio; IMD invasive meningococcal disease; MenB meningococcal serogroup B; $Q A F$ quality of life adjustment factor; $Q A L Y$ quality-adjusted life year; SOP standard operating procedure; STIKO Standing Committee on Vaccination (Ständige Impfkommission)

${ }^{a}$ For additional discounting scenarios applied to the base case and STIKO SOP scenario, see Supplemental Table S3

the significant productivity loss associated with the disease, with indirect cost savings predicted to be $€ 146.6$ ( $€ 153.5)$ million. The model considers the burden of MenB IMD (IMD) to patients in the acute phase and from long-term sequelae, the QALY impact on their family/caregivers and the economic burden beyond the healthcare system (education, public 


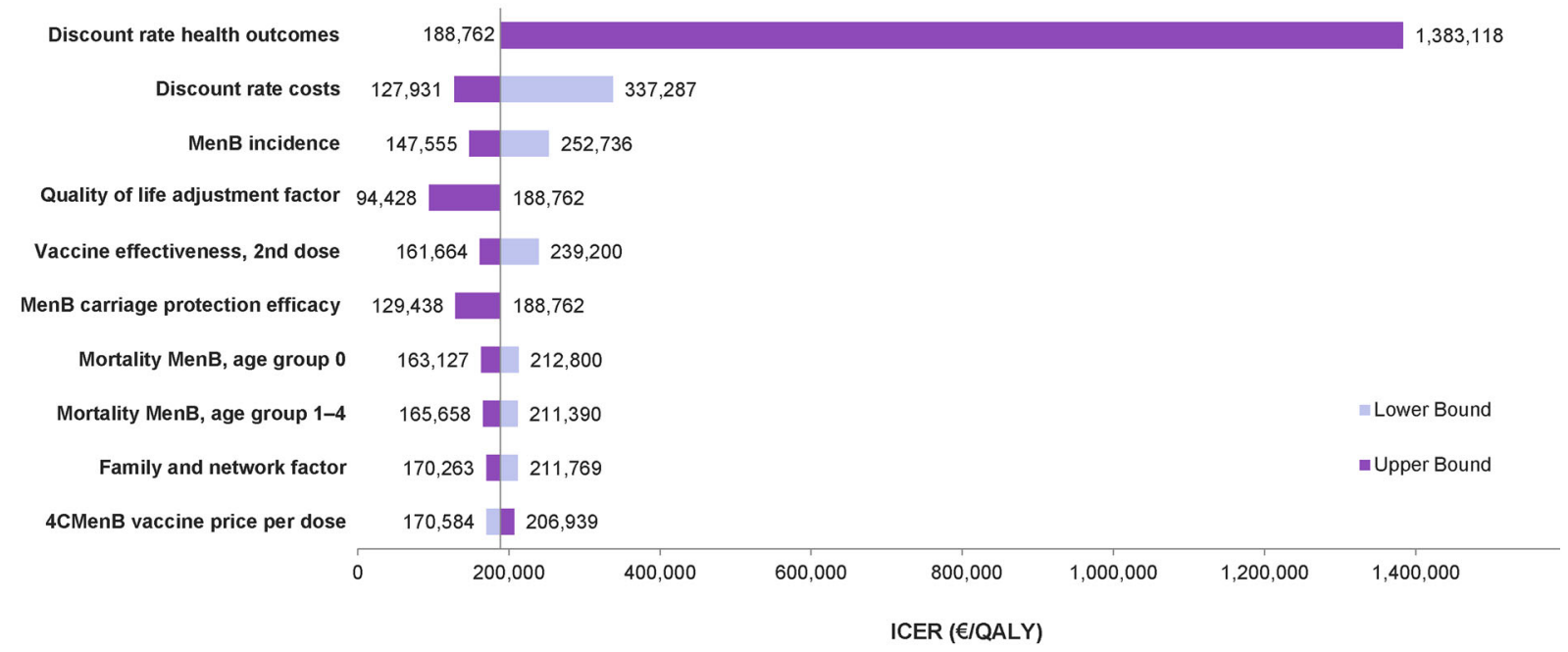

Fig. 3 Tornado diagram showing the 10 DSA results with the largest impact on the incremental cost-effectiveness ratio (ICER). $4 \mathrm{CMenB}$ four-component meningococcal serogroup B vaccine; DSA deterministic sensitivity analysis; MenB meningococcal serogroup B; QALY qualityadjusted life year

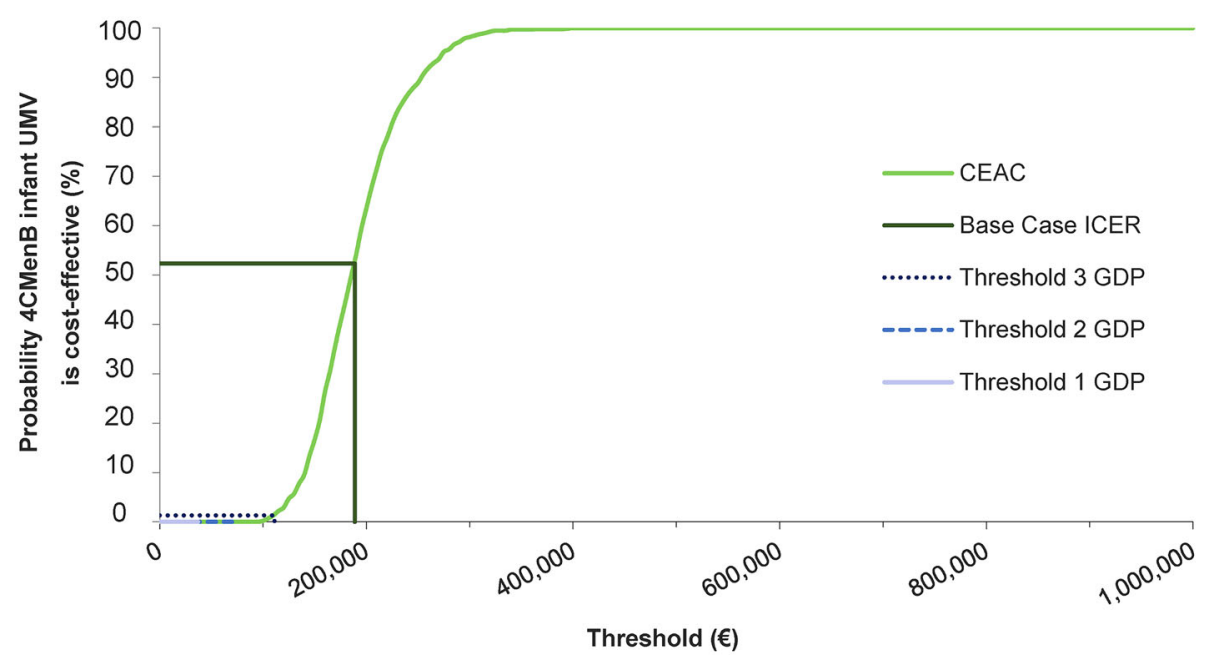

Fig. 4 Cost-effectiveness acceptability curve (CEAC) for hypothetical cost-effectiveness thresholds of $€ 37,046$ $(1 \times \mathrm{GDP}), \quad € 74, \quad 092 \quad(2 \times \mathrm{GDP})$ and $€ 111,138$ $(3 \times$ GDP $)$ per QALY gained. $4 \mathrm{CMenB}$ four-component

health), with a resulting incremental cost per QALY gained in Germany of $€ 188,762$, from the societal perspective. This ICER falls within the magnitude of the rotavirus infant UMV in Germany [51], estimated to be around $€ 117,000-143,000$ [52]. Rotavirus also affects meningococcal serogroup B vaccine; GDP gross domestic product; ICER incremental cost-effectiveness ratio; QALY quality-adjusted life year; UMV universal mass vaccination

infants but is less severe than IMD and more common.

Routine infant $4 \mathrm{CMenB}$ was included in the UK UMV in 2015 in a $2+1$ schedule (at 2, 4 and 12 months of age). After the first 3 years of the program with rapidly increasing vaccine uptake, real-world evidence showed a 
significant decline in IMD cases of $75 \%$ (95\% confidence interval $64-81 \%$ ) in the vaccine-eligible group aged 2-24 months olds [12]. Two regions of Italy that implemented routine infant 4CMenB using two different schedules also found significant declines in IMD cases in the vaccinated population $(91 \%$ and $80 \%$ relative case reductions), and a higher vaccine impact (i.e. effect considered in both vaccinated and unvaccinated children) in the region with a vaccination strategy starting early at 2 months of age compared with 7 months of age (65\% vs. 31\%) [53]. Following other European countries, in June 2021, France also recommended 4 CMenB starting at 2 months of age [11]. An early start of MenB vaccination (i.e. 2 months of age) is critical for a sustainable reduction of the MenB (IMD) induced burden of disease.

Our model is based on a dynamic transmission model by Huels et al. [54] which provided an extended version of the early model by Christensen et al. [55]. The economic results compare favourably to a previous IMD economic analysis conducted for Germany by Christensen et al. [13], which reported ICERs of over $€ 500,000$ and over $€ 1.9$ million per QALY gained for modelled strategies including and excluding indirect effects, respectively. In contrast to Christensen et al. [13], our model accounts for serogroups other than MenB that cause IMD and is thus able to include the effectiveness of $4 \mathrm{CMenB}$ against MenW and MenY IMD. In addition, our model utilises the latest data on the burden of disease in more detail with more accuracy, e.g. including the impact of IMD on 16 types of sequelae in patients (compared to three major and two minor sequelae in the Christensen et al. [13] model). Our model also includes the broader impact on QALY loss in family/caregivers beyond the patient. A recent claims database analysis found nearly a quarter of IMD cases in Germany suffered from sequelae [16], placing a considerable burden on the family/caregivers of survivors of IMD, as observed and measured in a large UK study of over 1200 families affected by IMD [24]. The costs included in our model were also based on a recent German costing study [17] providing a more comprehensive and accurate estimate of the lifetime costs of IMD, e.g. including costs of long-term institutional care and costs for all sequelae, which were not included in the previous German model. In Christensen et al. [13], the costs for the UMV were higher because of a $3+1$ dose schedule, compared to the $2+1$ dose schedule used here, based on the updated label [56], and as used in the UK and Portugal 4CMenB infant programs $[12,29]$.

As more evidence on input data becomes available, models need to use them to fully capture the value of vaccination. Including the full value using conservative health economic frameworks can be challenging, especially for UMVs for severe and uncommon diseases such as IMD with an unpredictable epidemiology [57]. The impact of new health economic modelling approaches that capture the full value of IMD vaccination [57] versus the STIKO modelling framework was illustrated in scenario analyses. For example, normative adaptations to the base case analysis according to STIKO's framework decreased the ICER from $€ 817,348$ to a base case of $€ 188,762$ (reduction of $77 \%$ ) with an initial reduction of -25 percentage points due to consideration of QALY losses beyond the patient (i.e. family QALY losses, a bereavement factor and QALY losses for formal long-term caregivers), and a further reduction of -52 percentage points due to applying a lower discount rate of $1 \%$ for health outcomes to account for the long-term health benefits of vaccination $[58,59]$. Discounting in modelling of vaccinations compared to other healthcare interventions has also been debated, since the costs of a vaccination program occur immediately while their health benefits may only be visible several years later $[60,61]$. By discounting the benefits of vaccination more heavily or equally compared to costs, vaccinations appear less beneficial than health interventions with rapidly evident benefits. Recent evidence from a French database analysis [62] has suggested that IMD significantly reduces life expectancy in survivors of the acute phase. Therefore, the life years (and QALYs) gained following vaccination in this analysis, and the subsequent cost-effectiveness of $4 \mathrm{CMenB}$, are likely to be underestimated. Future analyses should consider these additional benefits of $4 \mathrm{CMenB}$ vaccination with 
respect to the impact on the family and close network and to account for the long-term benefits of vaccination.

The current recommendation in Germany is for $4 \mathrm{CMenB}$ to be used in individuals at increased risk of IMD, such as household contacts of IMD cases and people with underlying immunologic deficiencies. In addition to immune deficiencies, a recent database analysis of IMD cases in France suggested that chronic medical conditions as well as low socioeconomic status may be risk factors for IMD hospitalisation [63]. A UMV can reduce the uncertainty due to unknown risk factors and protect those who may not be able to afford vaccination, as well as provide greater health benefits than targeted risk group vaccination recommendations, by preventing more disease in a larger group. The results of this analysis suggest that a 4 CMenB infant UMV will have important benefits in preventing this severe lifethreatening disease with the highest burden in infants and adolescents, at a lower cost-effectiveness ratio than previously estimated [13], and can be used to support decision-making towards a MenB infant UMV in Germany.

A key strength of this study is the use of a model that allows the comprehensive burden of IMD to be considered when evaluating the $\mathrm{UMV}$, i.e. the model includes the main serogroups causing IMD for the assessment of 4CMenB cross-protection effectiveness against multiple serogroups, a decision tree which includes a large range of potential short- and long-term sequelae resulting from IMD, and dynamic transmission for the evaluation of carriage and herd protection. As IMD is an uncommon disease, there are still many gaps in the data available especially for Germany. The model was, therefore, partly informed by input data from other countries (e.g. sequelae probabilities and utilities), as is common practice in economic evaluation. The model also did not consider the effects of potential strain replacement. To account for potential data uncertainty, numerous DSAs, a PSA and scenario analyses were conducted. In addition, IMD remains a disease with an unpredictable incidence and risk of outbreaks, making it difficult to model accurately. Existing models therefore need to make assumptions about incidence over time, and this model uses an average of incidence data over multiple years.

\section{CONCLUSIONS}

More evidence is now available on the burden and costs of IMD in Germany, and recent realworld evidence from the UK and Italy has demonstrated the significant benefits of routine $4 \mathrm{CMenB}$ vaccination. This updated analysis can inform decision-makers on the potential public health and health economic impact of a 4CMenB infant UMV in Germany. Our model showed that a UMV is predicted to rapidly reduce IMD cases and deaths in infants and young children, as well as the long-term burden of disease in survivors of the acute phase. Considering the broad-ranging impact to patients and their families/caregivers, routine $4 \mathrm{CMenB}$ is expected to provide additional health benefits to society at a cost of around $€ 189,000 /$ QALY gained and, with a more progressive scenario, results in an incremental cost of around $€ 78,000 / \mathrm{QALY}$ gained.

\section{ACKNOWLEDGEMENTS}

Funding. GlaxoSmithKline Biologicals SA funded this study (GSK study \# HO-17-19109) and all costs related to the development of the publication. GlaxoSmithKline Biologicals SA funded the Journal's Rapid Service Fee.

Medical Writing, Editorial, and Other Assistance. Markus Kirchner and Jens Vollmar provided technical support during data analyses. Emanuela Nyantakyi and Joffrey Baneton provided management and operational support during study conduct. The authors would like to thank Business \& Decision Life Sciences platform for editorial assistance and publication coordination, on behalf of GSK. Kavi Littlewood (Littlewood Writing Solutions) provided writing support and Lyes Derouiche coordinated publication development and editorial support. 
Authorship. All named authors meet the International Committee of Medical Journal Editors (ICMJE) criteria for authorship for this article, take responsibility for the integrity of the work as a whole, and have given their approval for this version to be published.

Author Contributions. Magdalena Schwarz, Stefan Scholz, Ekkehard Beck, Kinga Meszaros, Bernhard Ultsch and Wolfgang Greiner were involved in the conception or the design of the study. Magdalena Schwarz, Stefan Scholz, Ekkehard Beck, Kinga Meszaros and Bernhard Ultsch participated in the collection or generation of the data. All authors were involved in the analyses or interpretation of the data. All authors critically reviewed the manuscript and provided final approval on the submitted version. Writing of the first draft of the manuscript was led by Magdalena Schwarz and all authors commented on previous versions of the manuscript. All authors read and approved the final manuscript.

Prior Presentation. Abstract and poster presentation at the International Society for Pharmacoeconomics and Outcomes Research-23rd Annual European Congress 2020 (virtual conference).

Disclosures. Magdalena Schwarz is employed by the GSK group of companies. Stefan Scholz and Wolfgang Greiner report grants from the GSK group of companies during the conduct of the study. Ekkehard Beck, Bernhard Ultsch, Kinga Meszaros and Melanie Schneider are employed by the GSK group of companies and hold shares of the GSK group of companies. All authors declare no other financial or nonfinancial relationships and activities.

Compliance with Ethics Guidelines. This analysis uses data from previously conducted studies and does not contain any new studies with human participants or animals performed by any of the authors.

Data Availability. GSK makes available anonymized individual participant data and associated documents from interventional clinical studies that evaluate medicines upon approval of proposals submitted to www. clinicalstudydatarequest.com. To access data for other types of GSK sponsored research, for study documents without patient-level data and for clinical studies not listed, please submit an inquiry via the website.

Open Access. This article is licensed under a Creative Commons Attribution-NonCommercial 4.0 International License, which permits any non-commercial use, sharing, adaptation, distribution and reproduction in any medium or format, as long as you give appropriate credit to the original author(s) and the source, provide a link to the Creative Commons licence, and indicate if changes were made. The images or other third party material in this article are included in the article's Creative Commons licence, unless indicated otherwise in a credit line to the material. If material is not included in the article's Creative Commons licence and your intended use is not permitted by statutory regulation or exceeds the permitted use, you will need to obtain permission directly from the copyright holder. To view a copy of this licence, visit http://creativecommons.org/licenses/by$\mathrm{nc} / 4.0 /$.

\section{REFERENCES}

1. Nadel S, Ninis N. Invasive meningococcal disease in the vaccine era. Front Pediatr. 2018;6:321. https:// doi.org/10.3389/fped.2018.00321.

2. Christensen H, May M, Bowen L, Hickman M, Trotter CL. Meningococcal carriage by age: a systematic review and meta-analysis. Lancet Infect Dis. 2010;10(12):853-61. https://doi.org/10.1016/ s1473-3099(10)70251-6.

3. Booy R, Gentile A, Nissen M, Whelan J, Abitbol V. Recent changes in the epidemiology of Neisseria meningitidis serogroup $\mathrm{W}$ across the world, current vaccination policy choices and possible future strategies. Hum Vaccin Immunother. 2019;15(2): 470-80. https://doi.org/10.1080/21645515.2018. 1532248 .

4. Robert Koch Institut (RKI). Infektionsepidemiologisches Jahrbuch meldepflichtiger Krankheiten für 
2019. 2020. https://www.rki.de/DE/Content/Infekt/ Jahrbuch/Jahrbuecher/2019 Accessed May 2021.

5. Wang B, Clarke M, Thomas N, Howell S, Afzali HH, Marshall $\mathrm{H}$. The clinical burden and predictors of sequelae following invasive meningococcal disease in Australian children. Pediatr Infect Dis J. 2014;33(3):316-8. https://doi.org/10.1097/inf. 0000000000000043.

6. Viner RM, Booy R, Johnson H, et al. Outcomes of invasive meningococcal serogroup $\mathrm{B}$ disease in children and adolescents (MOSAIC): a case-control study. Lancet Neurol. 2012;11(9):774-83. https:// doi.org/10.1016/s1474-4422(12)70180-1.

7. Olbrich KJ, Müller D, Schumacher S, Beck E, Meszaros K, Koerber F. Systematic review of invasive meningococcal disease: sequelae and quality of life impact on patients and their caregivers. Infect Dis Ther. 2018;7(4):421-38. https://doi.org/10.1007/ s40121-018-0213-2.

8. Robert Koch Institut (RKI). Empfehlungen der Ständigen Impfkommission beim Robert Koch-Institut 2021. In: Epidemiologisches Bulletin 34 . 2021. https://www.rki.de/DE/Content/Infekt/ EpidBull/Archiv/2021/Ausgaben/34_21.pdf? blob=publicationFile. Accessed Sept 2021.

9. Martinón-Torres F, Banzhoff A, Azzari C, et al. Recent advances in meningococcal $\mathrm{B}$ disease prevention: real-world evidence from $4 \mathrm{CMenB}$ vaccination. J Infect. 2021;83(1):17-26. https://doi.org/ 10.1016/j.jinf.2021.04.031.

10. Bundesministeriums für Soziales G, Pflege und Konsumentenschutz. Impfplan Österreich. 2021. https://www.sozialministerium.at/Themen/ Gesundheit/Impfen/Impfplan-\%C3\%96sterreich. html. Accessed Aug 2021.

11. Haute Autorité de Santé (HAS). Méningocoques B : la HAS recommande la vaccination des nourrissons. 2021. https://www.has-sante.fr/jcms/p_3273097/. Accessed Sept 2021.

12. Ladhani SN, Andrews N, Parikh SR, et al. Vaccination of infants with meningococcal group $\mathrm{B}$ vaccine (4CMenB) in England. N Engl J Med. 2020;382(4): 309-17. https://doi.org/10.1056/NEJMoa1901229.

13. Christensen $\mathrm{H}$, Irving $\mathrm{T}$, Koch $\mathrm{J}$, et al. Epidemiological impact and cost-effectiveness of universal vaccination with Bexsero ${ }^{\circledR}$ to reduce meningococcal group $B$ disease in Germany. Vaccine. 2016;34(29):3412-9. https://doi.org/10.1016/j. vaccine.2016.04.004.

14. Robert Koch Institut (RKI). Aktualisierung der Meningokokken-Impfempfehlung: Anwendung des Meningokokken-B-Impfstoffs bei Personen mit erhöhtem Risiko für Meningokokken-Erkrankungen. 2015. https://edoc.rki.de/bitstream/handle/ 176904/2133/289uf2ZGslZfo.pdf?sequence= $1 \&$ isAllowed=y. Accessed 27 May 2021.

15. Robert Koch Institut (RKI). Aktualisierte Stellungnahme der Ständigen Impfkommission (STIKO) am Robert Koch-Institut (RKI)-Stand der Bewertung einer Impfung gegen Meningokokken der Serogruppe B. In: Epidemiologisches Bulletin 18(3). 2018. https://www.rki.de/DE/Content/Infekt/ EpidBull/Archiv/2018/Ausgaben/03_18.pdf? blob=publicationFile. Accessed 31 Aug 2021.

16. Huang L, Heuer OD, Janßen S, Häckl D, Schmedt N. Clinical and economic burden of invasive meningococcal disease: evidence from a large German claims database. PLoS One. 2020;15(1): e0228020. https://doi.org/10.1371/journal.pone. 0228020 .

17. Scholz S, Koerber F, Meszaros K, et al. The cost-ofillness for invasive meningococcal disease caused by serogroup B Neisseria meningitidis (MenB) in Germany. Vaccine. 2019;37(12):1692-701. https:// doi.org/10.1016/j.vaccine.2019.01.013.

18. Beck E, Klint J, Neine M, Garcia S, Meszaros K. Costeffectiveness of $4 \mathrm{CMenB}$ infant vaccination in England: a comprehensive valuation considering the broad impact of serogroup $B$ invasive meningococcal disease. Value Health. 2021;24(1): 91-104. https://doi.org/10.1016/j.jval.2020.09.004.

19. Hellenbrand W, Koch J, Harder T, et al. Background Paper for the update of meningococcal vaccination recommendations in Germany: use of the serogroup $B$ vaccine in persons at increased risk for meningococcal disease. Bundesgesundheitsblatt Gesundheitsforschung Gesundheitsschutz. 2015;58(11-12):1314-43. https://doi.org/10.1007/ s00103-015-2253-z.

20. Mossong J, Hens N, Jit M, et al. Social contacts and mixing patterns relevant to the spread of infectious diseases. PLoS Med. 2008;5(3):e74. https://doi.org/ 10.1371/journal.pmed.0050074.

21. Bettinger JA, Scheifele DW, Le Saux N, Halperin SA, Vaudry W, Tsang R. The disease burden of invasive meningococcal serogroup B disease in Canada. Pediatr Infect Dis J. 2013;32(1):e20-5. https://doi. org/10.1097/INF.0b013e3182706b89.

22. Szende A, Janssen B, Cabases J. Self-reported population health: an international perspective based on EQ-5D. Dordrecht: Springer; 2014.

23. Federal Statistical Office (FSO). Statistic 12621 "Lifetable: Germany, years, gender, completed age". 2018. https://www-genesis.destatis.de/genesis/ online?operation=statistic\&levelindex $=0$ \&levelid= 
$1620661618435 \&$ code $=12621$ \#abreadcrumb. Accessed May 2021.

24. Al-Janabi H, Van Exel J, Brouwer W, et al. Measuring health spillovers for economic evaluation: a case study in meningitis. Health Econ. 2016;25(12): 1529-44. https://doi.org/10.1002/hec.3259.

25. Gani R, Giovannoni G, Bates D, Kemball B, Hughes $\mathrm{S}$, Kerrigan J. Cost-effectiveness analyses of natalizumab (Tysabri) compared with other diseasemodifying therapies for people with highly active relapsing-remitting multiple sclerosis in the UK. Pharmacoeconomics. 2008;26(7):617-27. https:// doi.org/10.2165/00019053-200826070-00008.

26. Christensen H, Trotter CL, Hickman M, Edmunds WJ. Re-evaluating cost effectiveness of universal meningitis vaccination (Bexsero) in England: modelling study. BMJ. 2014;349: g5725. https:// doi.org/10.1136/bmj.g5725.

27. Song J, Floyd FJ, Seltzer MM, Greenberg JS, Hong J. Long-term effects of child death on parents' health related quality of life: a dyadic analysis. Fam Relat. 2010;59(3):269-82. https://doi.org/10.1111/j.17413729.2010.00601.x.

28. Rodrigues FMP, Marlow R, Simões MJ, Danon L, Ladhani S, Finn A. Association of use of a meningococcus group B vaccine with group B invasive meningococcal disease among children in Portugal. JAMA. 2020;324(21):2187-94. https://doi. org/10.1001/jama.2020.20449.

29. Sociedade Portuguesa de Pediatria (SPP). Recomendações sobre vacinas extra programa nacional de vacinação-atualização 2018. 2018. http:// criancaefamilia.spp.pt/media/127910/Vacinasextra-PNV-RecomendaCOes-SIP-SPP-2018.pdf. Accessed Sept 2021.

30. Martinon-Torres F, Safadi MAP, Martinez AC, et al. Reduced schedules of $4 \mathrm{CMenB}$ vaccine in infants and catch-up series in children: immunogenicity and safety results from a randomised open-label phase 3b trial. Vaccine. 2017;35(28):3548-57. https://doi.org/10.1016/j.vaccine.2017.05.023.

31. Weinberger R, von Kries R, van der Linden M, Rieck $\mathrm{T}$, Siedler A, Falkenhorst G. Invasive pneumococcal disease in children under 16 years of age: incomplete rebound in incidence after the maximum effect of PCV13 in 2012/13 in Germany. Vaccine. 2018;36(4):572-7. https://doi.org/10.1016/j. vaccine.2017.11.085.

32. Martinon-Torres F, Carmona Martinez A, Simko R, et al. Antibody persistence and booster responses 24-36 months after different $4 \mathrm{CMenB}$ vaccination schedules in infants and children: a randomised trial. J Infect. 2018;76(3):258-69. https://doi.org/ 10.1016/j.jinf.2017.12.005.

33. Biolchi A, De Angelis G, Moschioni M, et al. Multicomponent meningococcal serogroup $B$ vaccination elicits cross-reactive immunity in infants against genetically diverse serogroup $\mathrm{C}, \mathrm{W}$ and $\mathrm{Y}$ invasive disease isolates. Vaccine. 2020;38(47): 7542-50. https://doi.org/10.1016/j.vaccine.2020. 09.050 .

34. Vesikari T, Esposito S, Prymula R, et al. Immunogenicity and safety of an investigational multicomponent, recombinant, meningococcal serogroup B vaccine (4CMenB) administered concomitantly with routine infant and child vaccinations: results of two randomised trials. Lancet. 2013;381(9869):825-35. https://doi.org/10.1016/ s0140-6736(12)61961-8.

35. Bryan P, Seabroke S, Wong J, et al. Safety of multicomponent meningococcal group $\mathrm{B}$ vaccine $(4 \mathrm{CMenB})$ in routine infant immunisation in the UK: a prospective surveillance study. Lancet Child Adolesc Health. 2018;2(6):395-403. https://doi.org/ 10.1016/s2352-4642(18)30103-2.

36. Oberle D, Mentzer D, Keller-Stanislawski B. Bulletin zur arzneimittelsicherheit - Evaluation des Sicherheitsprofils eines Meningokokken-B-Impfstoffs auf Basis von Daten der Arzneimittelüberwachung nach Markteinführung. 2018. https://www.pei.de/ SharedDocs/Downloads/DE/newsroom/bulletinarzneimittelsicherheit/2018/2-2018.pdf?_blob= publicationFile\&v=2. Accessed Aug 2021.

37. Mentzer D, Oberle D, Keller-Stanislawski B. Adverse events following immunisation with a meningococcal serogroup B vaccine: report from post-marketing surveillance, Germany, 2013 to 2016. Eurosurveillance. 2018;23(17):17-00468. https:// doi.org/10.2807/1560-7917.ES.2018.23.17.1700468 .

38. Robert Koch Institut (RKI). Impfkalender 2020/2021. https://www.rki.de/DE/Content/Infekt/ Impfen/Materialien/Downloads-Impfkalender/ Impfkalender_Englisch.pdf?_blob=publicationFile . Accessed Aug 2021.

39. Nainani V, Galal U, Buttery J, Snape MD. An increase in accident and emergency presentations for adverse events following immunisation after introduction of the group B meningococcal vaccine: an observational study. Arch Dis Child. 2017;102(10):958. https://doi.org/10.1136/ archdischild-2017-312941.

40. CompuGroup Medical. https://www.lauer-fischer. de/. Accessed Aug 2021. 
41. Whelan J, Bambini S, Biolchi A, Brunelli B, Robert$\mathrm{Du}$ Ry van Beest Holle M. Outbreaks of meningococcal $\mathrm{B}$ infection and the $4 \mathrm{CMenB}$ vaccine: historical and future perspectives. Expert Rev Vaccines. 2015;14(5):713-36. https://doi.org/10.1586/ 14760584.2015.1004317.

42. Robert Koch Institut (RKI). SurvStat@RKI 2.0. https://survstat.rki.de/. Accessed Oct 2020.

43. Robert Koch Institut (RKI). STIKO (2016) Modelling methods for predicting epidemiological and health economic effects of vaccinations-Guidance for analyses to be presented to the German Standing Committee on Vaccination (STIKO) (last updated: 16 March 2016), Berlin. 2016.

44. Joint Committee on Vaccination and Immunisation (JCVI). Minute of the meeting on Tuesday 11 and Wednesday 12 February 2014. 2014.

45. Christensen H, Trotter CL. Modelling the cost-effectiveness of catch-up "MenB" (Bexsero) vaccination in England. Vaccine. 2017;35(2):208-11. https://doi.org/10.1016/j.vaccine.2016.11.076.

46. Marshall HS, McMillan M, Koehler AP, et al. Meningococcal B vaccine and meningococcal carriage in adolescents in Australia. $\mathrm{N}$ Engl J Med. 2020;382(4):318-27. https://doi.org/10.1056/ NEJMoa1900236.

47. Read RC, Baxter D, Chadwick DR, et al. Effect of a quadrivalent meningococcal ACWY glycoconjugate or a serogroup B meningococcal vaccine on meningococcal carriage: an observer-blind, phase 3 randomised clinical trial. Lancet. 2014;384(9960): 2123-31. https://doi.org/10.1016/s01406736(14)60842-4.

48. Kriz P, Wieffer $\mathrm{H}$, Holl $\mathrm{K}$, Rosenlund M, Budhia S, Vyse A. Changing epidemiology of meningococcal disease in Europe from the mid-20th to the early 21st century. Expert Rev Vaccines. 2011;10(10): 1477-86. https://doi.org/10.1586/erv.11.117.

49. Bertram MY, Lauer JA, DeJoncheere K, et al. Costeffectiveness thresholds: pros and cons. In: Bulletin of the World Health Organization 94:925-30. 2016. Accessed May 2021.

50. Statista. Bruttoinlandsprodukt (BIP) je Einwohner in Deutschland von 1991 bis 2020. 2021. https://de. statista.com/statistik/daten/studie/1252/umfrage/ entwicklung-des-bruttoinlandsprodukts-jeeinwohner-seit-1991/. Accessed May 2021.

51. Robert Koch Institut (RKI). Neuerungen in den aktuellen Empfehlungen der Ständigen Impfkommission (STIKO) am RKI vom August 2013. Epidemiologisches Bulletin Nr. 35:345-64. 2013. https://www.rki.de/DE/Content/Infekt/EpidBull/
Archiv/2013/Ausgaben/35_13.pdf?_blob= publicationFile. Accessed May 2021.

52. Aidelsburger P, Grabein K, Böhm K, et al. Cost-effectiveness of childhood rotavirus vaccination in Germany. Vaccine. 2014;32(17):1964-74. https:// doi.org/10.1016/j.vaccine.2014.01.061.

53. Azzari C, Moriondo M, Nieddu F, et al. Effectiveness and impact of the $4 \mathrm{CMenB}$ vaccine against group $\mathrm{b}$ meningococcal disease in two Italian regions using different vaccination schedules: a five-year retrospective observational study (2014-2018). Vaccines (Basel). 2020. https://doi.org/10.3390/ vaccines 8030469.

54. Huels J, Clements KM, Mc GL, Hill GJ, Wassil J, Kessabi S. Modelled evaluation of multi-component meningococcal vaccine (Bexsero ${ }^{\circledR}$ ) for the prevention of invasive meningococcal disease in infants and adolescents in the UK. Epidemiol Infect. 2014;142(9):2000-12. https://doi.org/10.1017/ s095026881300294x.

55. Christensen H, Hickman M, Edmunds WJ, Trotter CL. Introducing vaccination against serogroup B meningococcal disease: an economic and mathematical modelling study of potential impact. Vaccine. 2013;31(23):2638-46. https://doi.org/10. 1016/j.vaccine.2013.03.034.

56. European Medicines Agency (EMA). Bexsero-Summary of product characteristics. 2020. https://www. ema.europa.eu/en/documents/product-

information/bexsero-epar-product-information_en. pdf. Accessed Sept 2021.

57. Christensen H, Al-Janabi H, Levy P, et al. Economic evaluation of meningococcal vaccines: considerations for the future. Eur J Health Econ. 2020;21(2): 297-309. https://doi.org/10.1007/s10198-01901129-Z.

58. Bos JM, Beutels P, Annemans L, Postma MJ. Valuing prevention through economic evaluation. Pharmacoeconomics. 2004;22(18):1171-9. https://doi. org/10.2165/00019053-200422180-00002.

59. John J, Koerber F, Schad M. Differential discounting in the economic evaluation of healthcare programs. Cost Eff Resour Alloc. 2019;17(1):29. https://doi. org/10.1186/s12962-019-0196-1.

60. Ultsch B, Damm O, Beutels P, et al. Methods for health economic evaluation of vaccines and immunization decision frameworks: a consensus framework from a European vaccine economics community. Pharmacoeconomics. 2016;34(3): 227-44. https://doi.org/10.1007/s40273-015-03352. 
61. Jit M, Mibei W. Discounting in the evaluation of the cost-effectiveness of a vaccination programme: a critical review. Vaccine. 2015;33(32):3788-94. https://doi.org/10.1016/j.vaccine.2015.06.084.

62. Shen J, Bouée S, Aris E, et al. Long-term mortality and state financial support in invasive meningococcal disease-real-world data analysis using the French National Claims Database (SNIIRAM). Infect Dis Ther. 2021. https://doi.org/10.1007/s40121021-00546-z.

63. Taha M-K, Weil-Olivier C, Bouée S, et al. Risk factors for invasive meningococcal disease: a retrospective analysis of the French national public health insurance database. Hum Vaccin Immunother. 2021;17(6):1858-66. 21645515.2020 .1849518 . https://doi.org/10.1080/

\section{Publisher's Note}

Springer Nature remains neutral with regard to jurisdictional claims in published maps and institutional affiliations 